\title{
Caracterização molecular de populações do nematóide-de-cisto-da-soja com diferentes índices de parasitismo na cultivar Hartwig ${ }^{(1)}$
}

\author{
Ricardo Vilela Abdelnoor(2), Waldir Pereira Dias ${ }^{(2)}$, João Flávio Veloso Silva(2), \\ Silvana Regina Rockenbach Marin ${ }^{(2)}$ e Romeu Afonso de Souza Kiihl(2)
}

\begin{abstract}
Resumo - Recentemente, foi descoberta uma raça do nematóide-de-cisto-da-soja (NCS; Heterodera glycines) que apresentou a capacidade de quebrar a resistência da cultivar Hartwig, até então considerada resistente a todas as raças conhecidas do nematóide. Essa população foi coletada no Município de Sorriso, Estado do Mato Grosso, e foi caracterizada como raça 4. Para verificar a diversidade genética entre esta e outras populações pertencentes às raças 4 e 9 , foi feita uma caracterização molecular pela técnica de marcadores moleculares RAPD. Foram utilizadas nove populações do NCS, das quais quatro apresentavam a capacidade de parasitar 'Hartwig'. Foi verificado que as populações capazes de parasitar 'Hartwig' foram bastante diferentes das demais. Por meio de análise de agrupamento, com base nas distâncias genéticas encontradas, foram obtidos três grupos: o primeiro, constituído por indivíduos classificados como raça 4, mas que não parasitam 'Hartwig'; o segundo, constituído por quatro populações capazes de parasitar 'Hartwig', e o terceiro, por apenas uma população, classificado como raça 9, e que também não parasita 'Hartwig'. Este estudo confirmou que a população de NCS, encontrada em Sorriso, é geneticamente distinta das demais populações da raça 4 encontradas e constitui uma nova raça, denominada $4^{+}$.
\end{abstract}

Termos para indexação: Heterodera glycines, variação genética, marcadores moleculares, polimorfismo.

\section{Molecular characterization of soybean cyst nematode populations with different parasitism index to the Hartwig cultivar}

\begin{abstract}
Recently, a new race of soybean cyst nematode (SCN) (Heterodera glycines) was discovered, which breaks the resistance of cultivar Hartwig, resistant to all known races of SCN. This population was obtained from soybean plants collected in the Sorriso county, state of Mato Grosso, Brazil, and is characterized as race 4 . To verify if this isolate was different from others classified as races 4 and 9, their genetic diversity was analyzed by using the RAPD technique. Nine populations of SCN were analyzed, and only four populations were able to parasitize soybean plants cultivar Hartwig. Based on this study, it was verified that the populations that break Hartwig resistance were different from the other populations. Based on cluster analysis, the populations were separated into three groups. Race 4 populations were placed in the first group, while the race 9 population was placed in the second group and those capable of breaking cultivar Hartwig's resistance were placed in group three. This work confirms that the SCN population found in Sorriso is different from other isolates classified as race 4 , and was called race $4^{+}$.
\end{abstract}

Index terms: Heterodera glycines, genetic variation, molecular markers, polymorphism.

\footnotetext{
1 Aceito para publicação em 15 de fevereiro de 2000.

2 Embrapa-Centro Nacional de Pesquisa de Soja, Caixa Postal 231, CEP 86001-970 Londrina, PR.

E-mail: abdelnor@cnpso.embrapa.br,wdias@cnpso.embrapa.br, veloso@cnpso.embrapa.br, silvana@cnpso.embrapa.br, romeu@cnpso.embrapa.br
}

\section{Introdução}

O nematóide-de-cisto-da-soja (NCS), Heterodera glycines, foi encontrado pela primeira vez no Brasil em 1992, em seis municípios de quatro estados, e atualmente já está disseminado nas principais 
regiões produtoras de soja do País; foram identificadas as raças $1,2,3,4,5,6,9,10$ e 14, e a raça 3 é a mais difundida (Embrapa, 1998). Por essa grande variabilidade, o monitoramento da ocorrência e a distribuição das diferentes raças deste fitonematóide, em todo o Brasil, são feitos como atividade de rotina no laboratório de nematologia da Embrapa-Centro Nacional de Pesquisa de Soja, que subsidia a orientação de melhoristas engajados no desenvolvimento de novas cultivares resistentes.

Recentemente, no Município de Sorriso, MT, foi coletada uma população de NCS, que foi classificada como raça 4, de acordo com o esquema de caracterização proposto por Riggs \& Schmitt (1988). No entanto, foi verificado que essa população era capaz de parasitar a cultivar de soja Hartwig (Dias et al., 1998). Este foi o primeiro relato, em nível mundial, de uma população de campo de NCS com capacidade para quebrar a resistência da cultivar Hartwig, considerada resistente a todas as raças conhecidas do NCS. Esta cultivar apresenta genes de resistência oriundos da PI 437654, também resistente a todas as raças do NCS, mas que não teve sua resistência quebrada por esta população (Dias et al., 1998). A cultivar Hartwig vem sendo amplamente utilizada como fonte de genes de resistência a este parasita em todo o mundo, inclusive no Brasil, pois é a única fonte de resistência disponível para a raça 4 , presente nos estados de Goiás, Mato Grosso e Mato Grosso do Sul. O aparecimento dessa nova população torna ain- da mais complicado o controle deste nematóide nessas regiões.

Avanços na área de biologia molecular permitiram o desenvolvimento de técnicas de caracterização molecular. Entre as várias técnicas hoje disponíveis, o RAPD (Welsh \& McClelland, 1990; Williams et al., 1990) vem sendo utilizado com freqüência para análises de diversidade genética de diferentes tipos de fitopatógenos (Cobb \& Clarkson, 1993; Folkertsma et al., 1994; Fabre et al., 1995; Silva et al., 1995; Faleiro et al., 1998). O RAPD utiliza a técnica da reação em cadeia da polimerase (PCR) (Saiki et al., 1985) e se baseia na amplificação de fragmentos de DNA com o uso de "primers" de seqüência arbitrária. Este tipo de marcador se destaca principalmente pela facilidade e simplicidade das análises.

Com base no resultado encontrado por Dias et al. (1998), objetivou-se, neste trabalho, avaliar a diversidade genética entre algumas populações do NCS que não parasitam a cultivar Hartwig, e a população encontrada em Sorriso.

\section{Material e Métodos}

\section{Coleta e identificação de populações do NCS}

Foram avaliadas nove populações do NCS (Tabela 1), as quais foram mantidas em soja, sob condições de casa de vegetação, na Embrapa-Centro Nacional de Pesquisa de Soja (CNPSo). As populações de 1 a 6 foram coletadas

Tabela 1. Índice de parasitismo $(\%)$ de populações de Heterodera glycines inoculadas na série diferenciadora de soja para a identificação de $\operatorname{raças}^{(1)}$.

\begin{tabular}{llrrrrrrr}
\hline População & \multirow{2}{*}{ Origem } & \multicolumn{4}{c}{ Cultivares diferenciadoras } & \multicolumn{3}{c}{ Raça $^{(2)}$} \\
\cline { 3 - 7 } & & Pickett & Peking & PI 88788 & PI 90763 & Hartwig & Lee \\
\hline 1 & Chapadão do Céu, GO & 136,8 & 46,9 & 24,8 & 32,1 & 0,0 & 100 & 4 \\
2 & Chapadão do Céu, GO - Mara & 46,1 & 15,7 & 11,5 & 19,2 & 0,0 & 100 & 4 \\
3 & Faz. Cantinho do Céu, GO & 97,1 & 33,6 & 25,3 & 51,6 & 0,0 & 100 & 4 \\
4 & Faz. Padrão, MS & 73,9 & 22,2 & 15,4 & 30,3 & 0,0 & 100 & 4 \\
5 & Campos de Julho, MT & 72,5 & 16,2 & 3,1 & 2,9 & 0,0 & 100 & 9 \\
6 & Sorriso, MT-1 & 43,1 & 17,5 & 17,0 & 11,8 & 10,2 & 100 & $4^{+}$ \\
7 & Sorriso, MT-2 & 42,1 & 39,0 & 16,7 & 10,4 & 20,3 & 100 & $4^{+}$ \\
8 & Sorriso, MT-3 & 32,8 & 17,1 & 9,5 & 6,3 & 25,8 & 100 & $9^{+}$ \\
9 & Sorriso, MT-4 & 83,3 & 41,5 & 21,0 & 62,5 & 41,4 & 100 & $4^{+}$ \\
\hline
\end{tabular}

${ }^{(1)}$ Os valores dos índices de parasitismo foram calculados com base na média de fêmeas presentes em cinco repetições de cada diferenciadora. ${ }^{(2)} \mathrm{O}$ sinal + indica as raças que apresentam a capacidade de se multiplicar na cultivar Hartwig. 
diretamente de plantas de soja em lavouras infestadas por Heterodera glycines, e as populações 7, 8 e 9 foram originadas da população 6. Essas populações foram avaliadas para determinação de raça conforme eram recebidas no laboratório de nematologia da Embrapa-CNPSo.

Para a determinação do índice de parasitismo (IP) de cada população, foram colocadas para germinar em areia, sementes de cultivares de soja diferenciadoras de raças ('Pickett', 'Peking', PI 88788 e PI 90763), da cultivar Lee-68 (padrão de suscetibilidade) e da cultivar Hartwig. Dois dias após a emergência, as plântulas foram transferidas para vasos de argila com capacidade de $500 \mathrm{~g}$, contendo mistura de solo e areia na proporção de $1: 2$, previamente tratada com brometo de metila. Para a avaliação de cada população, foram usadas cinco repetições de cada genótipo (diferenciadoras, 'Lee-68' e 'Hartwig'), mantidas em delineamento inteiramente casualizado, em casa de vegetação. A inoculação em cada população foi feita um dia após o transplante, com a aplicação de $4 \mathrm{~mL}$ de uma suspensão de ovos (1.000 ovos/mL). Trinta dias após a inoculação, a parte aérea de cada planta foi eliminada, e o sistema radicular, cuidadosamente arrancado, posto em peneira de 20 mesh acoplada sobre uma de 60 mesh e lavado sob jato forte de água. As fêmeas retidas na peneira de 60 mesh foram transferidas para um papel-filtro e quantificadas em microscópio estereoscópico. O índice de parasitismo de cada genótipo foi calculado pela fórmula:

IP $=\frac{\text { Número médio de fêmeas na diferencia dora }}{\text { Número médio de fêmeas em 'Lee - 68' }} \times 100$

As raças foram determinadas conforme o esquema proposto por Riggs \& Schmitt (1988) e posteriormente por Dias et al. (1998) para as populações que se multiplicam na cv. Hartwig.

As fêmeas do NCS utilizadas para extração de DNA foram coletadas em tubo Eppendorf, na quantidade aproximada de 50-100 fêmeas brancas de cada população, e congeladas $\mathrm{a}-20^{\circ} \mathrm{C}$.

\section{Extração de DNA}

O DNA das fêmeas de cada população foi extraído conforme o método descrito por Doyle \& Doyle (1990), com algumas modificações: as fêmeas foram maceradas diretamente no tubo Eppendorf; a concentração de CTAB, no tampão, foi de 1\%; a concentração de B-mercaptoetanol, no tampão, foi de $0,1 \%$; PVP $1 \%$ foi adicionado ao tampão. O DNA obtido foi quantificado em espectrofotômetro a $260 \mathrm{~nm}$, conforme descrito por Sambrook et al. (1989) e estocado a $-20^{\circ} \mathrm{C}$.

\section{Análise de RAPD (Random Amplified Polymorphic DNA)}

Foi utilizado um total de 21 "primers" decâmeros (Operon Technologies) (Tabela 2) para amplificar o DNA extraído de cada uma das nove populações do nematóidede-cisto-da-soja. A mistura da reação de amplificação $(25 \mu \mathrm{L})$ era composta de $10 \mathrm{mM}$ Tris- $\mathrm{HCl}(\mathrm{pH} \mathrm{8,3)}$, $50 \mathrm{mM} \mathrm{KCl}, 2,4 \mathrm{mM}$ de $\mathrm{MgCl}_{2}, 100 \mu \mathrm{M}$ de cada deoxiribonucleotídeo, 0,4 $\mu \mathrm{M}$ do "primer", uma unidade da enzima Taq DNA polimerase (Gibco BRL), e $30 \mathrm{ng}$ de DNA. As reações foram feitas em um termociclador Perkin Elmer 9600 (Perkin Elmer Cetus, Norwalk, CT), programado para 45 ciclos de 15 segundos, a $94^{\circ} \mathrm{C}, 30$ segundos a $35^{\circ} \mathrm{C}$, e 1 minuto a $72^{\circ} \mathrm{C}$. Os produtos de amplificação foram separados por eletroforese horizontal, em gel de agarose $1,2 \%$ contendo brometo de etídio, e submerso em tampão TBE (0,09M Tris-Borato; 0,002M EDTA). O gel foi fotografado com filme polaróide 667 (abertura: 8; tempo: 1 segundo) sob iluminação de UV.

\section{Análise comparativa dos perfis de RAPD}

Os dados obtidos foram registrados na forma de presença (+) ou ausência (-) de bandas. As distâncias genéti-

Tabela 2. Relação dos "primers" de RAPD e suas seqüências de nucleotídeos, utilizados para a caracterização de nove populações de Heterodera glycines.

\begin{tabular}{ll}
\hline "Primer" & Seqüência (5’-3’) \\
\hline OPAA-02 & G A G A C C A G A C \\
OPAC-01 & T C C C A G C A G A \\
OPAC-02 & G T C G T C G T C T \\
OPAC-03 & C A C T G G C C C A \\
OPAC-04 & A C G G G A C C T G \\
OPAC-05 & G T T A G T G C G G \\
OPAC-06 & C C A G A A C G G A \\
OPAC-07 & G T G G C C G A T G \\
OPAC-08 & T T T G G G T G C C \\
OPAC-09 & A G A G C G T A C C \\
OPAC-10 & A G C A G C G A G G \\
OPAC-11 & C C T G G G T A G \\
OPAC-12 & G G C G A G T G T G \\
OPAC-14 & G T C G G T T G T C \\
OPAC-19 & A G T C C G C C T G \\
OPAC-20 & A C G G A A G T G G \\
OPAD-02 & C T G A A C C G C T \\
OPAD-11 & C A A T C G G G T C \\
OPAD-18 & A C G A G A G G C A \\
OPAG-10 & A C T G C C C G A C \\
OPAG-20 & T G C G C T C C T C \\
\hline
\end{tabular}

Pesq. agropec. bras., Brasília, v. 36, n. 2, p.331-337, fev. 2001 
cas entre as populações foram calculadas com base no complemento do coeficiente de similaridade de Nei e Li (Nei \& Li, 1979). Com base nas distâncias genéticas obtidas, foi elaborada a análise de agrupamento, pelo método da variância mínima, utilizando o programa estatístico SAEG (Euclides, 1983).

\section{Resultados e Discussão}

Das nove populações estudadas, sete se caracterizaram como sendo raça 4, e duas, raça 9 (Tabela 1), mas somente as populações 6, 7, 8 e 9 apresentaram capacidade de multiplicação na cultivar Hartwig, o que era o esperado, pois as amostras 7, 8 e 9 são originadas da população inicialmente coletada em Sorriso, MT (amostra 6). No entanto, uma dessas populações, a 8 , apesar de ser obtida a partir de uma população caracterizada como raça 4 , caracterizouse como raça 9, diferentemente das demais, cuja caracterização confirmou ser a raça 4 . Essa mudança de raça decorreu, provavelmente, da subjetividade do próprio teste de determinação de raças, que é baseado no esquema de Riggs \& Schmitt (1988). Esse esquema postula que as raças sejam determinadas com base nos índices de parasitismo observados em quatro diferenciadoras com relação a um suscetível padrão, em geral a cultivar Lee-68. No entanto esses índices podem ser bastante influenciados por diversos fatores, como temperatura, preparo do inóculo e heterogeneidade das sementes (Riggs et al., 1988). Além disso, as populações de NCS não são linhas puras, mas uma mistura de indivíduos com diferentes combinações gênicas, que podem ser afetados de diferentes maneiras por fatores externos, os quais podem favorecer determinados indivíduos e desfavorecer outros. Assim, o que vai determinar a raça de cada população será o fenótipo médio apresentado por ela. Variações na constituição genotípica de raças do NCS já foram verificadas também por outros autores (Riggs et al.,1988; Young, 1996), e estudos para padronização de procedimentos têm sido desenvolvidos para reduzir a variabilidade entre testes de raça (Riggs \& Schmitt, 1991). Apesar da padronização utilizada em todos os testes, a determinação das raças das nove populações utilizadas foi realizada em diferentes épocas, à medida que eram recebidas no laboratório. O mesmo ocorreu com as populações obtidas a partir da população 6 . Isto provavelmente influiu para a mudança de raça, visto que a temperatura da casa de vegetação e o solo utilizado não eram exatamente os mesmos. Para as populações que apresentam a capacidade de se multiplicar na cv. Hartwig, a designação da raça foi seguida do sinal (+), de acordo com a simbologia adotada por Dias et al. (1998).

Com os 21 "primers" utilizados, foram obtidos 126 produtos de amplificação (bandas no gel de agarose) que apresentaram alta reprodutibilidade e resolução, com uma média de seis bandas por "primer". Das 126 bandas obtidas, 89 foram polimórficas, ou seja, apresentaram diferenças pelo menos entre duas populações, e as 37 restantes apresentaram o mesmo padrão em todas as populações. O tamanho das bandas variou entre 360 e 2.250 pb (Figura 1).

A distância genética entre as populações do NCS variou de $0 \%$ a $45,0 \%$, de acordo com o resultado das amplificações (Tabela 3). Aquelas populações classificadas como raça $4^{+}$, e portanto, capazes de parasitar a cultivar Hartwig, foram diferentes das demais populações classificadas como raça 4 . O mesmo aconteceu com a população classificada como raça $9^{+}$. Esta foi diferente da população classificada como raça 9 (distância de 42,3\%) e bastante semelhante às outras populações que se reproduzem em 'Hartwig' (distância média de 1,9\%), mostrando, assim, que, apesar de ter havido mudança na caracterização da raça, a população continuou com a característica de 'quebra' da resistência da cv. Hartwig e com um genótipo muito semelhante ao das populações da raça $4^{+}$.

De acordo com as distâncias genéticas obtidas, foi possível realizar uma análise de agrupamento entre as nove populações, o que permitiu a formação de três grupos (Figura 2). O primeiro grupo foi composto com as quatro populações classificadas como raça 4. No segundo grupo ficaram as populações classificadas como raça $4^{+}$e raça $9^{+}$. No terceiro grupo ficou a população 5 , classificada como raça 9 , mostrando que é bastante diferente dos outros dois grupos. Esta população mostrou-se também bastante diferente da classificada como raça $9^{+}$. Dentro dos grupos, houve muito pouca variação. Entre populações ordenadas no primeiro grupo, as distâncias genéticas variaram de $0,7 \%$ a $2,1 \%$, ao passo que 
entre as populações do grupo 2 as distâncias variaram de $0 \%$ a 3,2\%. Entre populações de grupos diferentes, a distância ficou muito mais evidente. Entre os grupos 1 e 2, a distância média ficou em 33,54\%. Entre os grupos 1 e 3, a distância média ficou em $34,02 \%$, e entre os grupos 2 e 3, a distância média ficou em $42,55 \%$.
Alguns "primers" mostraram um padrão bem semelhante entre todos os indivíduos estudados, enquanto outros apresentaram bandas exclusivas para cada grupo obtido. Algumas bandas inclusive discriminaram populações que parasitam 'Hartwig' das que não parasitam (Figura 1). No entanto, não se pode afirmar que essas bandas podem ser utilizadas

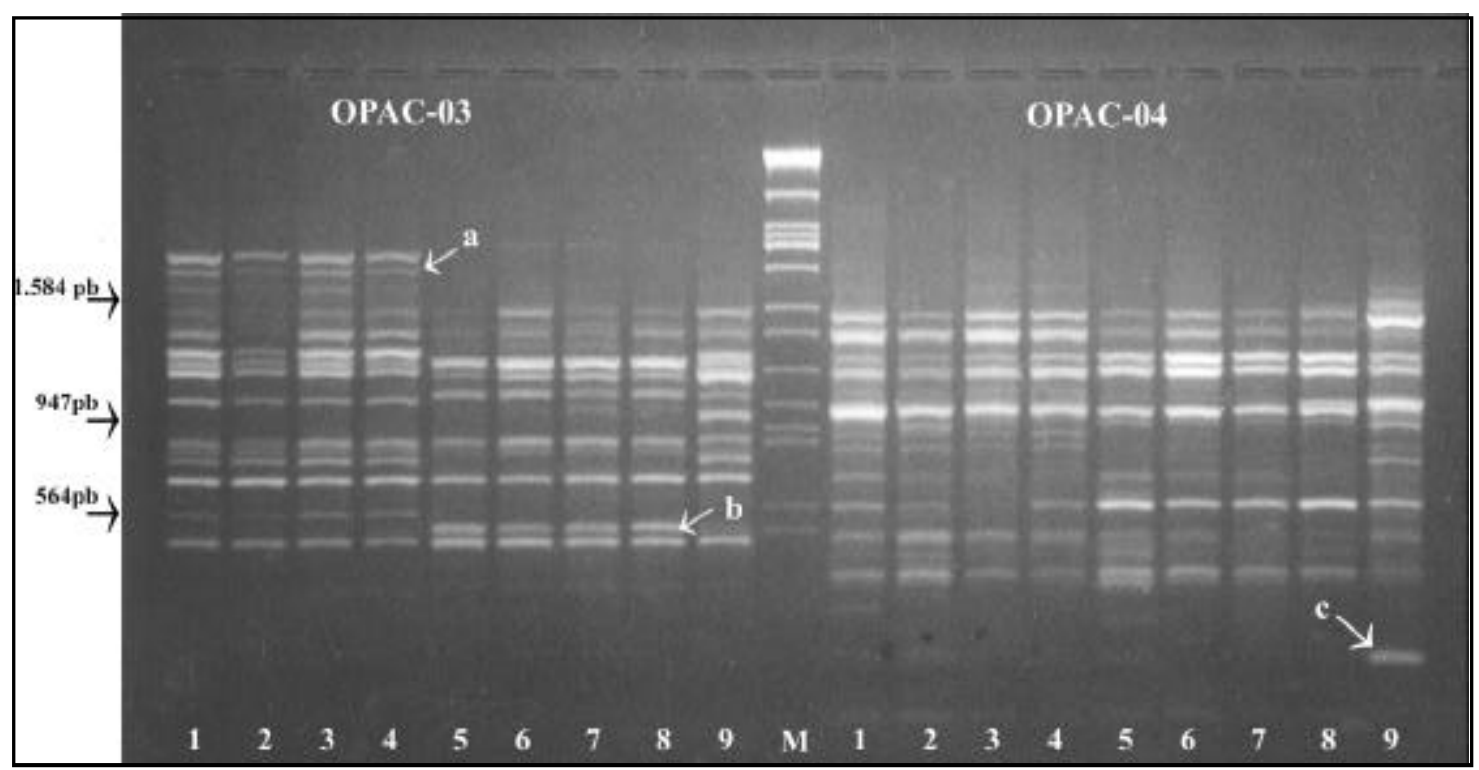

Figura 1. Análise de RAPD com os "primers" OPAC-03 e OPAC-04 de nove populações de Heterodera glycines. Amostras 1 a 3: raça 4+; amostra 4: raça 9+; amostras 5 a 8: raça 4; amostra 9: raça 9; M: marcador de peso molecular (DNA lambda digerido com as enzimas EcoR I, Hind III e BamH I). Os tamanhos de algumas bandas do marcador estão dispostos à esquerda da foto em pares de bases (pb). A seta (a) indica uma banda que separou as populações que se multiplicam na cultivar Hartwig das que não se multiplicam, (b) uma banda específica para raça 4, e (c) uma banda específica para raça 9.

Tabela 3. Matriz de distâncias genéticas obtidas entre nove populações de Heterodera glycines.

\begin{tabular}{|c|c|c|c|c|c|c|c|c|c|}
\hline $\begin{array}{c}\text { Origem da } \\
\text { população }^{(1)}\end{array}$ & $\begin{array}{c}1 \\
(\text { raça 4) }\end{array}$ & $\begin{array}{c}2 \\
(\text { raça 4) }\end{array}$ & $\begin{array}{c}3 \\
(\text { raça 4) }\end{array}$ & $\begin{array}{c}4 \\
\text { (raça 4) }\end{array}$ & $\begin{array}{c}5 \\
\text { (raça 9) }\end{array}$ & $\begin{array}{c}6 \\
\left(\text { raça } 4^{+}\right) \\
\end{array}$ & $\begin{array}{c}7 \\
\left(\text { raça } 4^{+}\right)\end{array}$ & $\begin{array}{c}8 \\
\left(\text { raça } 9^{+}\right)\end{array}$ & $\begin{array}{c}9 \\
\left(\operatorname{raça~} 4^{+}\right)\end{array}$ \\
\hline 1 & - & & & & & & & & \\
\hline 2 & 0,70 & - & & & & & & & \\
\hline 3 & 0,70 & 1,40 & - & & & & & & \\
\hline 4 & 1,40 & 2,10 & 2,10 & - & & & & & \\
\hline 5 & 33,80 & 35,20 & 33,30 & 33,80 & - & & & & \\
\hline 6 & 33,80 & 32,90 & 32,90 & 33,80 & 45,00 & - & & & \\
\hline 7 & 35,10 & 34,20 & 33,30 & 35,10 & 41,00 & 3,20 & - & & \\
\hline 8 & 33,80 & 32,90 & 32,00 & 35,10 & 42,30 & 3,20 & 2,50 & - & \\
\hline 9 & 33,30 & 32,40 & 31,50 & 34,60 & 41,90 & 3,30 & 2,50 & 0,00 & - \\
\hline
\end{tabular}

(1) 1: Chapadão do Céu, GO; 2: Chapadão do Céu, GO - Mara; 3: Fazenda Cantinho do Céu, GO; 4: Fazenda Padrão, MS; 5: Campos de Julho, MT; 6: Sorriso, MT-1; 7: Sorriso, MT-2; 8: Sorriso, MT-3; 9: Sorriso, MT-4. 


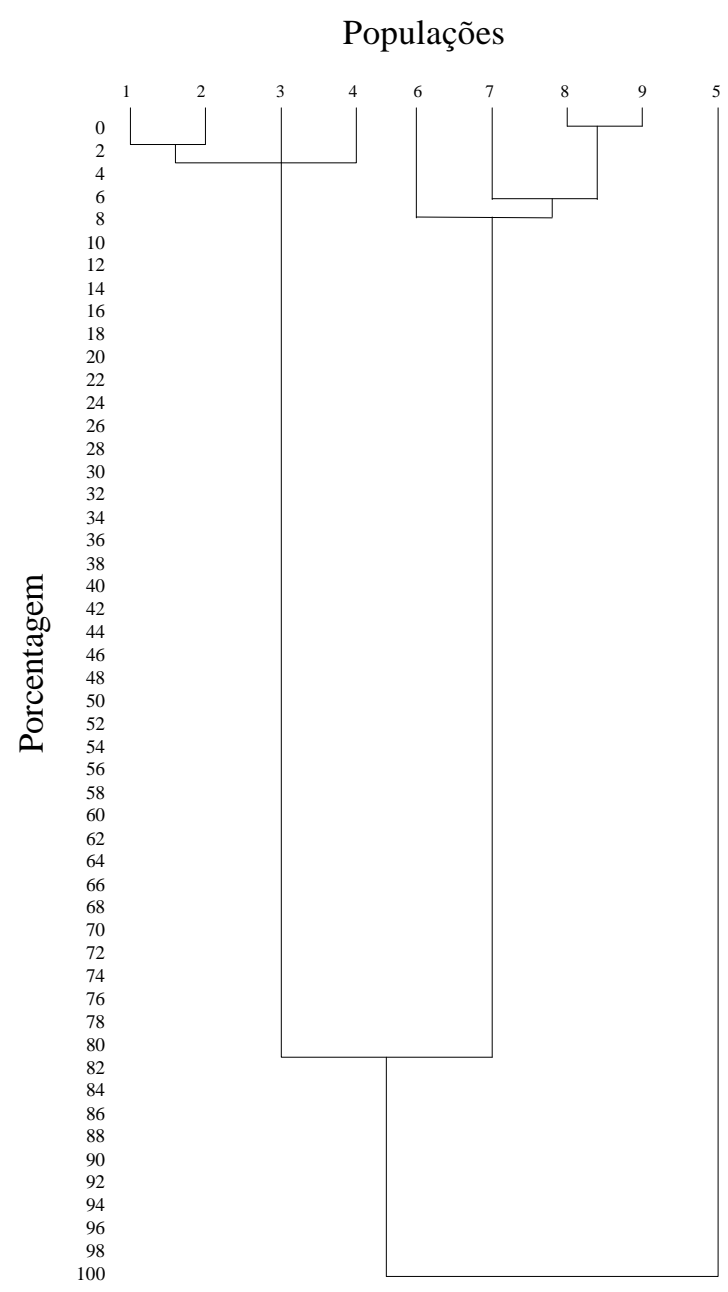

Figura 2. Dendrograma originado da análise de agrupamento de nove populações de Heterodera glycines a partir de marcadores RAPD. A análise foi feita pelo método da variância mínima com base nas distâncias genéticas. Origem das populações: 1: Chapadão do Céu, GO; 2: Chapadão do Céu, GO-Mara; 3: Fazenda Cantinho do Céu, GO; 4: Fazenda Padrão, MS; 5: Campos de Julho, MT; 6: Sorriso, MT-1; 7: Sorriso, MT-2; 8: Sorriso, MT-3; 9: Sorriso, MT-4.

para a caracterização racial, pois o número de testes realizados foi muito reduzido. Apenas ficou evidenciado que as populações classificadas em uma mesma raça apresentam várias regiões genômicas comuns. Um estudo mais completo, envolvendo todas as raças já identificadas no Brasil, provenientes de amostras de todas as regiões onde este nematóide ocorre, já está sendo realizado. Com isso, será possível verificar a relação desta raça $4^{+}$com todas as demais e talvez confirme a possibilidade do uso destes marcadores na caracterização de raças do NCS.

\section{Conclusões}

1. A técnica de RAPD permite verificar diferenças no conjunto gênico que compõe diferentes raças do nematóide-de-cisto-da-soja.

2. As populações originadas de Sorriso, MT, que conseguem se multiplicar na cultivar Hartwig (raças $4^{+}$e $9^{+}$), são geneticamente diferentes das demais populações, que não são capazes de tal multiplicação (raças 4 e 9).

\section{Referências}

COBB, B. D.; CLARKSON, J. M. Detection of molecular variation in the insect pathogenic fungus Metarhizium using RAPD-PCR. FEMS Microbiology Letters, Amsterdam, v. 112 , p. $319-324,1993$.

DIAS, W. P.; SILVA, J. F. V.; KIIHL, R. A. S.; HIROMOTO, D. M.; ABDELNOOR, R. V. Quebra da resistência da cv. Hartwig por população de campo do nematóide de cisto da soja. Pesquisa Agropecuária Brasileira, Brasília, v. 33, n. 6, p. 971-974, jun. 1998.

DOYLE, J. J.; DOYLE, J. L. Isolation of plant DNA from fresh tissue. Focus, Gaithersburg, v. 12, p. 13-15, 1990.

EMBRAPA. Centro Nacional de Pesquisa de Soja (Londrina, PR). Recomendações técnicas para a cultura da soja na região central do Brasil 1998/99. Londrina, 1998. 182 p. (Embrapa-CNPSo. Documentos, 120).

EUCLIDES, R. F. Sistema para análise estatística genética - SAEG. Viçosa : Imprensa Universitária, 1983. $57 \mathrm{p}$.

FABRE, J. V.; JULIEN, J.; PARISOT, D.; DRON, M. Analysis of diverse isolates of Colletotrichum lindemuthianum infecting common bean using molecular markers. Mycological Research, Cambridge, Grã-Bretanha, v. 99, n. 4, p. 429-435, 1995.

FALEIRO, F. G.; RAGAGNIN, V. A.; MESQUITA, A. G. G.; VINHADELLI, W. S.; PAULA JÚNIOR, T. J.; MOREIRA, M. A.; BARROS, E. G. Genetic diversity of isolates of Uromyces appendiculatus with the aid of RAPD 
molecular markers. Fitopatologia Brasileira, Brasília, v. 23, n. 3, p. 386-390, 1998.

FOLKERTSMA, R. T.; VOORT, J. N. A. M. R. van der; GENT-PELZER, M. P. E. van; GROOT, K. E. de; BOS, W. J. van de; SCHOTS, A.; BAKKER, J.; GOMMERS, F. J. Inter and intraspecific variation between populations of Globodera rostochiensis and G. pallida revealed by random amplified polymorphic DNA. Phytopathology, St. Paul, v. 84, n. 8, p. 807-811, 1994.

NEI, M.; LI, W. H. Mathematical model for studying genetic variation in terms of restriction endonucleases. National Academy of Sciences of the United States of America Proceedings, Washington, v. 76, p. 5269-5273, 1979.

RIGGS, R. D.; SCHMITT, D. P. Complete characterization of the race scheme for Heterodera glycines. Journal of Nematology, Eaton Park, v. 20, n. 3, p. 392$395,1988$.

RIGGS, R. D.; SCHMITT, D. P. Optimization of the Heterodera glycines race test procedure. Journal of Nematology, Eaton Park, v. 23, n. 2, p. 149-154, 1991.

RIGGS, R. D.; SCHMITT, D. P.; NOEL, G. R. Variability in race tests with Heterodera glycines. Journal of Nematology, Eaton Park, v. 20, n. 4, p. 565-572, 1988.
SAIKI, R. K.; SCHARF, S. J.; FALOONA, F.; MULLIS, K. B.; HORN, G. T.; ERLICH, H. A.; ARNHEIN, N. Enzymatic amplification of beta-globin genomic sequences and restriction analysis for diagnosis of sickle cell anemia. Science, Washington, v. 230, p. 1350-1354, 1985.

SAMBROOK, J.; FRITSCH, E. F.; MANIATIS, T. Molecular cloning: a laboratory manual. 2. ed. New York : Cold Spring Harbor Laboratory, 1989. v. 3.

SILVA, W. P. K.; MULTANI, D. S.; DEVERALL, B. J.; LYON, B. R. RFLP and RAPD analyses in the identification and differentiation of isolates of the leaf spot fungus Corynespora cassiicola. Australian Journal of Botany, Collingwood, v. 43, p. 609-618, 1995.

WELSH, J.; McCLELLAND, M. Fingerprinting genomes using PCR with arbitrary primers. Nucleic Acids Research, Oxford, v. 18, n. 24, p. 7213-7218, 1990.

WILLIAMS, J. G. K.; KUBELIK, A. R.; LIVAK, K. J.; RAFALSKI, J. A.; TINGEY, S. V. DNA polymorphism amplified by arbitrary primers are useful as genetic markers. Nucleic Acids Research, Oxford, v. 18, n. 22, p. 6531$6535,1990$.

YOUNG, L. D. Advising growers in selection of Heterodera glycines-resistant soybean cultivars. Journal of Nematology, Eaton Park, v. 28, n. 4s, p. 608-611, 1996. Supplement. 